\title{
De conexão, prevenção e reunião de processos: multiplicidade de fases de operações como critério de fixação de competência
}

\section{Connection, prevention and the reunion of criminal cases: multiplicity of phases of police operations as a criterion for establishing competence}

\section{Eugênio Pacelli de Oliveira}

\section{Matheus Oliveira de Carvalho}

Resumo: 0 texto aborda, essencialmente, dois pontos de tensão referentes à temática da conexão, ambos a ver com a distribuição da ação penal a determinado juízo em detrimento de outro investido na mesma competência territorial, sob a declarada finalidade de se evitar decisões judiciais contraditórias, invariavelmente utilizada para justificar, de todo modo, reuniões de processos. A primeira inquietação levantada questiona, em grande parte dos casos, a necessidade de afastamento prévio que se faz de um ou mais juízes - igualmente competentes - que poderiam também e legitimamente avaliar de sua competência, caso a ação fosse distribuída aleatoriamente pelos critérios do art. 75, CPP. Chama-se atenção especialmente para os casos, cada vez mais comuns, em que uma mesma operação policial se desdobre em inúmeras fases, o que se prestaria a justificar a permanência, até a última delas, da competência do juízo vinculado ao início da operação, sobretudo a partir de eventuais identidades de fontes probatórias, resultantes apenas de casualidade, com as quais se busca estabelecer vínculos entre fatos que, no mais das vezes, não atingem o nível da conexidade exigido pela lei processual. Em um segundo momento, 0 texto busca a desconstrução da crença comum de que a conexão, ordinariamente, viria acompanhada do risco de decisões conflitantes. A partir do estudo pormenorizado de cada uma das hipóteses legais de conexão, chega-se à definição daquele que seria o ponto essencial a que todo risco de decisões conflitantes (na conexão) poderia ser reconduzido.

Palavras-chave: conexão; critério de distribuição; prevenção; multiplicidade de fases de operações policiais; risco de decisões conflitantes.

Abstract: The text essentially addresses two points of tension regarding the theme of connection, both related to the distribution of the criminal action to a given court in detriment to another invested in the same territorial jurisdiction, 
with the stated purpose of avoiding contradictory court decisions, invariably used to justify, in any case, process meetings. The first concern raised questions, in most cases, the need for prior removal of one or more judges equally competent - who could also legitimately assess their competence, if the action were randomly distributed according to the criteria of art. 75 of the brazilian Penal Procedure Code. Attention is especially drawn to cases, which are increasingly common, in which the same police operation unfolds into numerous phases, which would justify the permanence, until the last one, of the jurisdiction of the court linked to the beginning of the Operation, especially from possible identities of evidentiary sources, resulting only from chance, with which one seeks to establish links between facts that, in most cases, do not reach the level of connectedness required by procedural law. In a second moment, the text seeks to deconstruct the common belief that the connection, ordinarily, would come with the risk of conflicting decisions. Based on a detailed study of each of the legal connection hypotheses, we arrive at the definition of what would be the essential point to which any risk of conflicting decisions (in connection) could be brought back.

Keywords: connection; distribution criterion; prevention; multiplicity of phases of police operations; risk of conflicting decisions.

Sumário: 1 Introdução: tema e problemas; 2 A escolha de juízos universais, com subtração da matéria aos demais; 3 Conexão: definição e conceitos; 4 As hipóteses de conexão no Direito brasileiro; Referências.

\section{Introdução: tema e problemas}

A síntese mínima de problemas eventualmente maximizáveis que serão aqui tratados gira em torno das regras de distribuição e de reunião de processos, quando em virtude do que se conhece por conexão entre fatos submetidos ou a serem submetidos à jurisdição penal. No plano abstrato, a questão não oferece maiores dificuldades. Distribuição é um dos critérios de determinação da competência, pressuposta a superação de alguns outros, que lhe antecedem e de que são exemplos o lugar e a natureza da infração (art. 69, CPP). Conexão é a relação de intimidade ou de proximidade entre fatos, em nível suficiente a recomendar-se a reunião de processos, para finalidades de interesse público no bom funcionamento da Justiça.

As controvérsias surgem mesmo é no cotidiano da vida forense, cuja complexidade nem sempre se subsome nas hipóteses legais. Se esse costuma ser o desafio frequente e até esperado na dogmática jurídica, outros há que podem se identificar como má compreensão ou o mau uso de conceitos operacionalmente funcionais. Nesse passo, e nesse ponto, a Ciência há de cumprir seus compromissos e exigir explicações mais convincentes daqueles que atuam na práxis.

A ver, então, o que se anda fazendo em torno de distribuições de ações penais a juízos previamente identificados, ou seja, por alegada dependência a outro processo e sem a submissão à regra da aleatoriedade, nos casos de existência de 
mais de um juiz com igual competência para a causa (art. 75, CPP). Obviamente que não estamos a cuidar daqueles casos em que a distribuição se faz por vinculação direta à tramitação judicial da investigação antecedente à ação penal, sobretudo quando esse juízo tenha praticado ato de conteúdo decisório (art. 83, (PP), hipótese modelo da prevenção.

O problema, de fato, é outro. Ele ocorre quando se argumenta com as regras de conexão já por ocasião da distribuição da ação penal, dirigida, por isso mesmo, a um juiz específico. Conexão, bem se sabe, constitui, ao menos em geral, critério de modificação de competência, pressupondo, portanto, mais de um processo em curso (art. 78, CPP), valendo registrar a excepcionalidade da unidade de denúncia, isto é, aquelas situações em que os fatos alegadamente conexos são objeto de uma única e mesma peça acusatória.

A outra indagação a ser enfrentada diz respeito a uma das justificativas geralmente utilizadas para a reunião de processos tramitando em juízos diferentes, a se dar cumprimento às normas contidas no art. 79 e no art. 82, ambos do CPP, cuja aplicação se encontra vinculada aos critérios dispostos no art. 76 do mesmo Código. A inquietação que ora se levanta se ajusta à declarada finalidade de se evitar decisões judiciais contraditórias, invariavelmente utilizada para justificar as reuniões de processos, ainda quando inexista por completo o apontado risco.

\section{A escolha de juízos universais, com subtração da matéria aos demais}

Iniciemos pelo primeiro, em homenagem à ordem natural das coisas, reminiscência metodológica já em desuso. Qual o problema em se distribuir uma ação penal diretamente a um juiz, de igual competência a de outro, partindo-se da premissa de que haveria conexidade entre os fatos tratados na ação antecedente, que lá tem curso, e aqueles veiculados nessa última, assim distribuída?

No plano abstrato, avulta mesmo é afastamento prévio que se faz de um ou mais juízes - igualmente competentes - que poderiam também e legitimamente avaliar sua competência, caso a ação fosse distribuída aleatoriamente pelos critérios do art. 75, CPP. Dirigindo-se a distribuição por dependência, ou seja, por alegada conexidade com fatos de ação ali sob tramitação, caberá apenas àquele juiz previamente escolhido o exame da matéria, nas hipóteses em que ele aceitar sua competência, reconhecendo a conexão entre os dois processos.

Mas a grande questão que se põe, a bem da verdade, é de outra natureza ou de outra ordem. Na prática, a antecedência na distribuição de investigações, geralmente acompanhadas da prática de atos cautelares, tem se prestado à for- 
mação de juízos universais sobre determinadas matérias, assim entendido o juízo que se apresentaria como o juiz nacional para aquela operação. O mote justificador da prevenção, assim, passa a ser a própria operação.

O movimento investigativo e processual penal que se dispôs a vincular fatos diversos a uma mesma base comum, afastada dos limites e dos critérios legais de determinação da competência e da reunião de processos, tem nome e sobrenome, a depender de cada uma delas, mas todas reunidas no mesmo Código associativo: as (diversas) fases de uma mesma operação. Foi essa ideia, agigantada sobremaneira naquela que recebeu o nome de Lava Jato, que consagrou e consolidou o desrespeito aos critérios legais de fixação da competência por conexão.

Não compactuaremos com a demonização acrítica de tais operações, como se nelas residisse todos os erros e pecados do mundo, e, mais, como se eles (erros e pecados) estivessem em níveis superiores da reprovação dirigida aos crimes então investigados e apurados. Jamais e em tempo nenhum.

Mas os bons e mesmo os melhores propósitos não garantem a valia do resultado, nem purificam a má conduta movida por tais finalidades. Do ponto de vista exclusivamente processual, isto é, no campo do devido processo legal, os desvios praticados por agentes da persecução penal merecem até maior censura. Naquela específica operação, os proveitos foram imensos; os defeitos também, e, porém.

E a metodologia de ação parece ter se espalhado Brasil afora, com a mídia noticiando, não sem certa avidez, as novas fases e os supostos desdobramentos de operações tornadas notórias por ela mesma.

Assim, fatos não relacionados àqueles que deram início à determinada investigação - sob a rubrica de operação - foram apropriados como se conexos fossem, para fins de justificação da prevalência de determinada jurisdição. Onde se via instrumentalidade probatória emergia muito mais identidade de compreensão jurídica entre a acusação e a jurisdição. Pode haver mesmo conexão relevante, a ponto de justificar a reunião de processos, entre fatos de $1^{\text {a }}$ fase e outros de $30^{a}$, de uma mesma operação?

Nesse passo, tudo vem se prestando a justificar a permanência do juízo vinculado ao início da operação, sobretudo a partir de eventuais identidades de fontes probatórias, resultantes apenas de casualidade, com as quais se buscava e se busca ainda estabelecer vínculos duradouros e irreversíveis entre fatos sequer conexos. 
Por que não se ouviu e não se ouve outro magistrado, detentor, também ele, de mesma competência, para a clarificação da incidência, ou não, da regra da conexão? Qual o problema em se distribuir aleatoriamente a ação penal, e, depois, se reivindicar a prevalência de um deles e a necessidade de reunião de processos, para unidade de julgamento?

De outra parte, a identidade de fonte probatória, isto é, o surgimento contemporâneo de provas de crimes diversos a partir de uma mesma medida cautelar (busca e apreensão, interceptação de dados ou telefônica) pode caracterizar apenas o fenômeno do encontro fortuito de prova, insuficiente, de per si, para se adequar às hipóteses do art. 76, CPP. É para isso que se prevê a possibilidade de compartilhamento de provas, entre juízos distintos. Não há em tais situações a necessidade, e tampouco estará justificada, a unidade de processo (art. 79, CPP).

Releva notar e acentuar, sobre tudo isso, que a competência territorial do juiz legal - única que estamos a ver, dado que o vício de incompetência absoluta é ainda mais grave - também se insere como garantia processual fundamental. O fato de ser possível a sua relativização, nas situações em que a defesa aceita a perpetuactio jurisdictionis, não diminui o seu status de garantia.

Em data ainda muito recente, e tratando da anulação de rumoroso processo originário da Operação Lava Jato, o douto Ministro Fachin, Relator, assentou as seguintes considerações:

Conclui-se, portanto, que o Ministério Público Federal, à época em que aforou a denúncia em desfavor do paciente, já tinha ciência da extensão alcançada pelas condutas que lhe foram atribuídas, as quais abarcaram não só a Petrobras S/A, mas outros órgãos públicos, sociedades de economia mista e empresas públicas no âmbito das quais, com semelhante modus operandi, foram celebradas contratações revestidas de ilicitudes, em benefício espúrio de agentes públicos, agremiações partidárias e empreiteiras. Optou-se, à época, pela concentração dos feitos relacionados ao aludido grupo criminoso no âmbito da competência da 13ํㅡ Vara Federal da Subseção Judiciária de Curitiba, dentre os quais o caso ora sob análise. [...]

Mas não cuida a exordial acusatória de atribuir ao paciente uma relação de causa e efeito entre a sua atuação como Presidente da República e determinada contratação realizada pelo Grupo OAS com a Petrobras S/A, em decorrência da qual se tenha acertado o pagamento da vantagem indevida. $\mathrm{Na}$ estrutura delituosa delimitada pelo Ministério Público Federal, ao paciente são atribuídas condutas condizentes com a figura central do grupo criminoso organizado, com ampla atuação nos diversos órgãos pelos quais se espalharam a prática de ilicitudes, sendo a Petrobras S/A apenas um deles, 
conforme já demonstrado em excerto colacionado da exordial acusatória. O caso, portanto, não se amolda ao que veio sendo construído e já decidido no âmbito do Plenário e da Segunda Turma do Supremo Tribunal Federal a respeito da competência da 13 $3^{\underline{a}}$ Vara Federal de Curitiba, delimitada, como visto, exclusivamente aos ilícitos praticados em detrimento da Petrobras S/A. [...]

Em todos os casos, as denúncias foram estruturadas da mesma forma daquela ofertada nos autos da Ação Penal no 5046512-94.2016.4.04.7000/PR, ou seja, atribuindo-lhe o papel de figura central do grupo criminoso organizado, com ampla atuação nos diversos órgãos pelos quais se espalharam a prática de ilicitudes, sendo a Petrobras S/A apenas um deles. Com efeito, de acordo com a narrativa exposta pelo Ministério Público Federal em denúncia oferecida nos autos da Ação Penal no 5063130-17.2018.4.04.7000/PR, na mesma espacialidade, o paciente teria recebido do Grupo Odebrecht vantagens indevidas consistentes "em um imóvel para a instalação do Instituto Lula", à época avaliado em R \$ 12.422.000,00; bem como no "apartamento no 121 do Residencial Hill House, bloco 1, localizado na Avenida Francisco Prestes Maia, 1.501, São Bernardo do Campo/SP", avaliado em R\$ 504.000,00. Não há, contudo, o apontamento de qualquer ato praticado pelo paciente no contexto das específicas contratações realizadas pelo Grupo Odebrecht com a Petrobras S/A, o que afasta, por igual, a competência da $13^{\underline{a}}$ Vara Federal de Curitiba ao processo e julgamento das acusações. ${ }^{1}$

O que se extrai dessa decisão, acompanhada, quanto à conclusão, pelos demais membros daquela $2^{a}$ Turma, é que o vício então reconhecido se fundava no fato de se tratar de denúncia com pluralidade de imputações e que envolveria mais de uma vítima, além da Petrobras, sociedade de economia mista.

Maxima venia, há aí outros equívocos. O primeiro deles é o de vincular a competência daquele juízo de Curitiba aos delitos praticados contra a Petrobras, como se a identidade de vítima pudesse consagrar regra processual de prevenção. Nem a vítima, nem o autor e tampouco o modus operandi constituem critério de conexão.

Com efeito, o que há de definir os contornos mais seguros da conexão é a necessidade de unidade de processo e julgamento, nos precisos termos do art. 79, CPP. É dizer, o ponto ou os pontos de contato entre os processos e entre os fatos há de ser de tal monta que a reunião deles em uma mesma jurisdição, não só 
facilite a instrução criminal, mas, sobretudo, permita a ampliação da visão acerca da materialidade e da autoria dos fatos conexos, e, de modo especial, no âmbito da participação. Somente a reunião de processos, por exemplo, poderá possibilitar a identificação de partícipe de delito praticado por outros (autores), quando a sua atuação não emergir deste último processo.

Um mesmo autor pode praticar vários crimes, de uma mesma maneira, em tempos e locais distintos, e ainda assim não haver qualquer conexidade entre eles. Se for importante para a corroboração da autoria, nada impede o aproveitamento do compartilhamento da prova, para fim de associar aquele comportamento a outros anteriores e do mesmo agente. Mas nem sempre será necessária a reunião dos processos. Não se deve subestimar o afastamento do juiz legal, cuja competência decorre, não da Constituição, mas da legislação processual penal. Trata-se de garantia fundamental da defesa.

De igual modo, a vítima, e, no caso, a Petrobras, pode ser atingida em inúmeras infrações penais e, ainda assim, não se impor a instituição de um juiz nacional para tais violações. Fatos praticados no Rio de Janeiro devem lá ser julgados, pelo juiz territorialmente competente, após definida a jurisdição constitucional para a causa. Assim como aqueles realizados em São Paulo, Pernambuco, Minas Gerais e nos demais Estados brasileiros. Para todos eles há juiz natural e também juiz legal, valendo lembrar o risco de instituição de juiz de exceção, aí, sim, fato muitíssimo mais grave que os equívocos de competência.

Identidade de vítima, de autor e a utilização do mesmo modus operandi, portanto, podem até ser úteis à compreensão de fatos de maior complexidade investigativa, mas não podem determinar a subtração do juiz natural e tampouco do juiz legal para o processo. Nem sempre se deve reunir processos em um mesmo juízo; pelo contrário, a regra é em sentido diverso. Repita-se: há solução ao alcance, pelo compartilhamento de provas. Apenas quando indispensável é que se deve privilegiar a unidade de processo para a unidade de julgamento, a bem de interesses legítimos e essenciais da jurisdição, única maneira de se justificar a quebra da garantia do juiz legal.

Encerra-se o ponto, enfim. Não pode haver juiz nacional com competência firmada pela identidade da vítima e tampouco pelo modelo comum de atuação. Se a vítima tem atuação e representação em vários locais do País, como ocorre com a Petrobras, nada justificaria ou justificou o acúmulo de competência que se verificou em Curitiba, com a chancela dos demais Tribunais. Recorre-se, assim, ao apogeu e à cumeada da filosofia popular: uma coisa é uma coisa; outra coisa é outra coisa. 


\section{Conexão: definição e conceitos}

Ao se atribuir à conexão a rubrica de critério de prorrogação ou modificação da competência, se dirá mais e propriamente de seus efeitos do que de seu conteúdo. A conexão é, antes disso, o vínculo que identifica ou conecta em alguma medida determinados fatos (nesse sentido se trata de um fenômeno pré-processual2), e cuja repercussão processual sintetiza-se na decorrente identificação parcial de objeto, causa de pedir, partes ou, quando nada, objeto da prova de dois ou mais processos ${ }^{3}$.

É conhecida a lição segundo a qual "O vínculo que estabelece a conexidade, retirando a independência das infrações, é um vínculo de causalidade" ${ }^{\prime \prime}$, usualmente referido à conexão objetiva ${ }^{5}$, mas elevado a substrato comum da conexão por Galdino Siqueira e Espíndola Filho, na doutrina nacional. Em síntese, o reconhecimento da conexão exigiria a verificação de uma de duas relações: (i) de dependência de causa idêntica entre os delitos (ou seja, que ambos ou todos possam ser redirecionados a uma mesma origem ou contexto); ou (ii) de causa e efeito entre um e outro(s) ${ }^{6}$.

Às hipóteses de conexão se chegará mais adiante. O que, de todo modo, deve estar esclarecido é que a eleição daqueles vínculos que relevam, efetivamente, para fins de conexidade, embora sujeita à "estrita conveniência e oportunidade, na qual se conduz, incensuravelmente, o legislador" ${ }^{\prime \prime}$, orienta-se essencialmente segundo o seguinte juízo: A boa administração da atividade jurisdicional melhor se obtém com a reunião de quais processos?

Veja-se que a concentração da atividade probatória em um único processo, para além de traduzir ganho inequívoco em economia e celeridade na resolução do caso, tem a oferecer, com o julgamento conjunto, aquela visão do todo ${ }^{8}$, de

2 XAVIER DE ALBUQUERQUE, Revista de Doutrina e Jurisprudência 1, p. 43.

3 Na lição de Xavier de Albuquerque (ob. cit., p. 41): "[...] com todas as insuficiências que se the possam apontar, ainda é a velha regra dos três eadem a fórmula menos flutuante, e por isso mais útil, para a configuração da conexão em sua projeção processual: duas causas podem dizer-se conexas, quando entre elas existe a comunhão de algum dos elementos que as identificam (eadem personae, eadem res, eadem causa petendi). Não é que a conexão consista nessa comunhão, mas que através dela se manifesta no processo". ESPÍNDOLA FILHO, Código de Processo Penal brasileiro anotado, p. 180.

5 Neste sentido, FREDERICO MARQUES, Elementos de direito processual penal I, p. 257-258; BADARÓ, Processo penal, p. 300-301.

6 ESPÍNDOLA FILHO, ob. cit., p. 180-182.

7 XAVIER DE ALBUQUERQUE, ob. cit., p. 43.

8 Nesse sentido, Florian (Elementos de derecho procesal penal, p. 167-168): "Podemos, pues, decir que la conexión se verifica: a) por razón de la persona; b) por el delito; c) por la prueba. Em todos estos casos sería inoportuno y 
outro modo prejudicada com a cisão de fatos por vezes essencialmente imbricados. Nas hipóteses de conexão intersubjetiva por concurso (em que há pluralidade de crimes e autores em concurso de agentes), parece inegável, por exemplo, o avanço obtido ao nível da identificação da autoria dos fatos que estejam em questão.

Mas eis o segundo ponto deste texto. Para além das finalidades já expostas, costuma-se apontar uma outra, que justificaria com ainda mais razão a reunião de processos conexos: a evitação de decisões conflitantes ${ }^{9}$. O problema, contudo, é que tão frequente como o recurso ao tal argumento é a ausência de resposta ao inevitável questionamento: Por que e em que medida a conexão implicaria esse risco?

A impressão que se tem ao consultar a doutrina majoritária ${ }^{10}$ e a jurisprudência nacional que cuida do assunto (mais adiante examinada) é a de que tamanha obviedade dispensaria o esforço da explicação. De nossa parte, não estamos convencidos de que uma prejudicialidade nesses termos seja imediatamente acessível, e tampouco que esteja presente em toda e qualquer hipótese de conexão. Ao contrário, aliás, nem pensamos que seja a regra.

E a relevância da identificação dos casos em que esteja, efetivamente, presente o risco de decisões conflitantes se visualiza naquelas hipóteses em que a conexão se verifica entre processos cuja reunião tensionaria a observância ao princípio do juiz natural: ou seja, quando a reunião dos processos deva se dar em detrimento de determinado juízo cuja competência de jurisdição ${ }^{11}$ seja diversa daquele em favor do qual se operaria a prorrogação da competência.

hasta prejudicial fraccionar el proceso em distintos procedimientos para cada delito o procesado; la apreciación de sólo una parte ocultaría el sentido conjunto fraccionándolo, y la responsabilidad de cada sujeto no apareceria precisa ni clara. El criterio que se sigue para evitar esto es hacer competente para conocer de todos los delitos al juez que desde el principio sea competente para conocer del mayor".

9 Na lição de Jorge de Figueiredo Dias, "a razão justificativa da imposição da conexão será, antes de tudo, de economia processual. Mas não só, pois a ela acrescem - quando não mesmo se sobrepõem - razões de boa administração da justiça penal (juntando processos conexos será provavelmente mais esgotante a produção probatória e respetiva cognição) e mesmo de prestígio das decisões judiciais (pois desaparecerá o perigo de uma pluralidade de decisões sobre infrações conexas se contradizerem materialmente)" (FIGUEIREDO DIAS; BRANDÃO, Sujeitos processuais penais.

10 Por todos, Frederico Marques afirma que "a conexão, além de contribuir para a economia processual, evita decisões divergentes ou contraditórias, e, por possibilitar uma visão mais completa dos fatos e da causa, constitui fator de melhor aplicação jurisdicional do direito" (FREDERICO MARQUES, ob. cit., p. 254). De outro lado, sustenta que o risco de decisões conflitantes somente existiria nas hipóteses de continência, LOPES JÚNIOR, Direito processual penal e sua conformidade constitucional I, p. 412.

11 Segundo Pacelli de Oliveira (Curso de processo penal, p. 232), "a competência de jurisdição, portanto, é aquela posta na Constituição da República, primeiro como garantia individual e segundo como estruturação e repartição 
Isso porque, em casos tais, apoiando-se a conexão unicamente em razões de otimização da atividade probatória, como regra, o proveito da instrução (do processo) não vale o risco da jurisdição (constitucional). Havendo, contudo, o risco da convivência de decisões contraditórias, e com isso a violação à unidade da jurisdição ${ }^{12}$ - e, no limite, ao princípio da isonomia -, altera-se a ordem de prioridade. Como, aliás, e exatamente pelas mesmas razões, se passa com as hipóteses de continência: sob o risco de pronunciamentos judiciais conflitantes sobre uma só questão de fato, justifica-se, como regra, a reunião. Mesmo em se tratando de juízos com competências de jurisdição diversas.

Eis, então, as hipóteses de conexão previstas no Direito brasileiro e as possibilidades de decisões contraditórias eventualmente implicadas em cada uma delas.

\section{As hipóteses de conexão no Direito brasileiro}

São essencialmente três as hipóteses de conexão trazidas no Código de Processo Penal: a conexão intersubjetiva, a objetiva ${ }^{13}$ e a instrumental (ou probatória). Abaixo, a redação do artigo 76:

Art. 76. A competência será determinada pela conexão:

I - se, ocorrendo duas ou mais infrações, houverem sido praticadas, ao mesmo tempo, por várias pessoas reunidas, ou por várias pessoas em concurso, embora diverso o tempo e o lugar, ou por várias pessoas, umas contra as outras;

II - se, no mesmo caso, houverem sido umas praticadas para facilitar ou ocultar as outras, ou para conseguir impunidade ou vantagem em relação a qualquer delas;

III - quando a prova de uma infração ou de qualquer de suas circunstâncias elementares influir na prova de outra infração.

constitucional do poder de jurisdição. É na Constituição que se elege a competência ratione materiae e ratione personae - e, mais, remete-se à legislação ordinária a competência em razão do lugar".

12 Já escrevemos que "não se pode perder de vista que a unidade da jurisdição, princípio pelo qual se espera o mesmo pronunciamento judicial sobre a mesma questão de fato, caso da continência (art. 77), impõe, como valor igualmente constitucional, a adoção de critérios de competência que possam minimizar ao máximo a ocorrência das apontadas divergências" (PACELLI DE OLIVEIRA, ob. cit., p. 296).

Também chamada de material, consequencial ou teleológica. 
À saída, convém um brevíssimo esclarecimento metodológico. Embora se tenha individualizado o quanto possível o exame das hipóteses legais, pareceu inevitável o constante retorno a uma ou outra delas, e por duas razões: a uma, é bastante frequente que estejam presentes na mesma situação mais de uma hipótese de conexão, e, a duas, pensamos que uma delas estará sempre presente quando verificado o risco de decisões conflitantes - daí sua proeminência nas linhas que seguem.

Pois bem. A conexão intersubjetiva (inciso I) dá-se, como visto, em três hipóteses ${ }^{14}$ : (i) por simultaneidade quando, ocorrendo duas ou mais infrações, houverem sido praticadas ao mesmo tempo, por duas ou mais pessoas reunidas; (ii) por concurso, quando duas ou mais infrações são cometidas por duas ou mais pessoas em concurso, embora em tempo e lugares diversos; e (iii) por reciprocidade, quando sejam cometidas as infrações por várias pessoas, umas contra as outras.

Na já citada classificação de Galdino Siqueira, no caso da conexão intersubjetiva por simultaneidade, ambos os delitos dependeriam de uma causa comum ocasional, ao passo que nas outras duas hipóteses (intersubjetiva por concurso e por reciprocidade), "teremos a dependência, dos delitos, de uma causa comum direta, não ocasional"15.

A conexão intersubjetiva trata, como soa intuitivo, da conexão fundada na identificação entre os sujeitos implicados nos diversos fatos sob apuração, vinculados entre si por uma relação intencional (concursal), temporal ou de reciprocidade. É exemplo ilustrativo do primeiro caso a seguinte hipótese, recolhida da jurisprudência do Superior Tribunal de Justiça:

Evidenciado, por meio de diálogos obtidos em interceptações telefônicas, que os presos em flagrante transportavam fuzil de propriedade de terceiro envolvido com quadrilhas dedicadas ao assalto a bancos e a carros-fortes, e constatado que um deles (o falecido) possuía larga ficha de antecedentes criminais ligando-o ao proprietário da arma de fogo de uso restrito das Forças Armadas, depreende-se que, no momento em que foram flagrados, os indivíduos executavam uma das tarefas de esquema voltado para a consecução

14 Optou-se, aqui, pela classificação mais recorrente na doutrina nacional, adotada, entre outros, por FREDERICO MARQUES, ob. cit., p. 254; BADARÓ, ob. cit., p. 299-300. 
eficiente de crimes de roubo a bancos, carros-fortes e empresas de transporte de valores. Daí a nítida conexão intersubjetiva [...]. ${ }^{16}$

Pois bem. No que diz ao problema aqui colocado, não nos parece que o fato em si considerado da identificação entre os sujeitos a quem se imputa diversos delitos implique, por si só (com a vênia pela insistência), o risco de decisões conflitantes. Pode ocorrer, por exemplo, mas circunstancialmente, que estejam em questão o furto (ou o contrabando) de mercadorias e a posterior receptação daquelas, imputada a outros agentes em um determinado contexto. Nesse caso, pensamos que seria manifesta a prejudicialidade e, nesse sentido, a possibilidade de decisões conflitantes. Mas o que parece justificar a reunião dos processos sob um tal argumento (risco de decisões contraditórias) não será a constatação da conexão intersubjetiva, mas a conexão objetiva ali verificada, e que ocorrerá, nos termos do inciso II do artigo 76: "II - se, no mesmo caso, houverem sido umas praticadas para facilitar ou ocultar as outras, ou para conseguir impunidade ou vantagem em relação a qualquer delas; [...]".

Veja-se que não se cogita, aqui, da concomitância, pluralidade de agentes ou concerto prévio entre esses: nada disso se exige ao reconhecimento da conexão objetiva (ou material). Trata-se daquele vínculo de conexidade fundamentado na já mencionada relação de causa e efeito diretamente estabelecida ${ }^{17}$. Note-se, então, que, "no Direito pátrio, os casos de conexão objetiva não se coadunam com a chamada relação ocasional de causa e efeito. Nas hipóteses previstas pelo art. 76, II, a relação de antecedente para consequente tem um sentido nitidamente teleológico e intencional"18. Dito de outro modo, exige-se que uma das infrações seja cometida para (com a intenção de) facilitar ou ocultar as demais, conseguir a impunidade ou ainda (para) obter vantagem referente a qualquer delas.

Naturalmente, pode-se argumentar que a reunião de agentes em um determinado contexto criminoso que envolva a prática de crimes (mais de um) envolverá, com maior frequência, alguns (crimes) que se implicarão mutuamente em uma relação possivelmente prejudicial. Com o que até se pode concordar, aliás. Mas sob o aviso já registrado de que o receio de decisões conflitantes estará aí fundamentado não exatamente na conexão intersubjetiva, mas na conexão ob-

17 Há, ainda, a relação de causa e efeito ocasionalmente estabelecida, que ocorre, por exemplo, no caso "do agente de polícia, o qual, na perseguição de um delinquente preso em flagrante e escapulira, mata o fugitivo, sem qualquer necessidade de defesa" (ESPÍNOLA FILHO, ob. cit., p. 182). 
jetiva ou, ainda, na conexão instrumental (inciso III do artigo supracitado), mais adiante aprofundada, e que ocorrerá: "III - quando a prova de uma infração ou de qualquer de suas circunstâncias elementares influir na prova de outra infração".

Voltando-se, contudo e por ora, à conexão intersubjetiva, agora por reciprocidade (crimes cometidos por várias pessoas, umas contra as outras), pensamos que esteja pressuposto nessas hipóteses um determinado grau de vinculação entre os delitos que, frequentemente, exigirá a reunião de processos, sob o risco de prolação de decisões conflitantes. Isso porque, embora até seja possível que a reciprocidade se dê à ausência de um nexo de causa e efeito entre as condutas de uns e outros, pensamos que ele esteja usualmente presente no exemplo clássico dessa hipótese legal, ou seja, o das lesões corporais recíprocas (que ultrapassem o contexto da rixa $\left.{ }^{19}\right)$. E que decorra daí a prejudicialidade que é objeto particular deste texto.

Ora, não parece raro que surjam, nesses casos, indícios consistentes de que uma parcela dos envolvidos somente atuou em revide a lesões já iniciadas pelos demais. Nesse caso, a reunião de processos evitaria que se chegasse, por exemplo, ao seguinte cenário: em um determinado juízo, reconhece-se a legítima defesa daqueles que atuaram posteriormente, ao passo que no juízo encarregado do processo referente aos que atuaram em primeiro lugar absolve-se igualmente os acusados com fundamento na justificação da conduta, que somente teria ocorrido para repelir a iminente agressão daqueles outros. Pois bem. Justificada a agressão praticada em primeiro lugar, não haveria que se falar em legítima defesa dos que atuaram em seguida ${ }^{20}$.

E na hipótese em questão, veja-se que não estará presente a conexão objetiva: não se trata de qualquer conduta "praticada para facilitar ou ocultar as outras, ou para conseguir impunidade ou vantagem em relação a qualquer delas" ${ }^{21}$. De outro lado, nada desautoriza a conclusão de que "a prova de uma infração ou de qualquer de suas circunstâncias elementares" tenha influído "na prova de outra infração" 22 . Isso porque a comprovação da iminência da agressão vinda do segundo grupo de agentes, na medida em que justificaria a conduta dos primeiros, faria desaparecer a "infração", e, nesse sentido, constitui (parte da) prova desse processo. De outro lado, e porque a justificação daquela conduta interdita a veri-

19 Nesse caso, trata-se de delito único, a configurar, portanto, a hipótese de continência.

20 Isso porque 0 art. 25 do CP exige para a configuração da legítima defesa que a agressão repelida seja injusta.

21 É essa a redação do art. 76, II, do CPP.

22 Tal a redação do dispositivo trazido no art. 76, III, do CPP. 
ficação da legítima defesa em questão no segundo processo, naturalmente trata-se de prova que influi na prova de outra infração.

Não parece, aliás, circunstancial que as decisões encontradas na jurisprudência nacional que reconhecem a conexão intersubjetiva e determinam a reunião de processos com a finalidade de se evitar decisões contraditórias estejam sempre acompanhadas de igual menção à conexão probatória, essa efetivamente relevante, ao nosso juízo, para a consecução da finalidade declarada. É ver, por exemplo:

A Terceira Seção, por unanimidade de votos, conheceu do Conflito de Competência $\mathrm{n}^{\mathrm{O}}$ 145.705/DF e, com base na previsão do parágrafo $2^{\circ}$, do artigo 71, do Regimento Interno desta Corte e em precedente do Supremo Tribunal Federal, declarou competente o Ministro Felix Fischer para processar e julgar os casos decorrentes da denominada Operação Lava-Jato, "desde que constatados os requisitos da interligação entre os sujeitos e organizações envolvidas, além da vinculação probatória". ${ }^{23}$

Portanto, há conexão intersubjetiva e probatória ou teleológica, na medida em que as provas reunidas na operação "Ponto Final" acerca desse esquema paralelo de contabilidade à serviços de pagamentos indevidos será crucial [sic] para definir se a imputação proposta procede ou não. ${ }^{24}$

O acolhimento da tese de que a conexão somente poderia ser reconhecida para casos posteriores à fixação da prevenção do Ministro Felix Fischer esvaziaria completamente o instituto da conexão, possibilitando a prolação de decisões díspares, a despeito do reconhecimento do liame subjetivo e probatório entre os procedimentos judiciais. ${ }^{25}$

Naturalmente, não será toda e qualquer influência exercida pela prova do cometimento de um delito ou de qualquer de suas circunstâncias elementares que bastará à configuração do risco de pronunciamentos decisórios conflitantes. É verdade que a lei deixou de minudenciar o grau de conexidade probatório exigido $^{26}$ na hipótese do inciso III, ao que lhe sobreveio o rótulo de "laço mais tênue

23 STJ, CC 145.589/DF, 3a Seção, Rel. Min. Joel Ilan Paciornik, J. 27.04.2016, DJe 04.05.2016.

24 STJ, RHC 138.029, Rel. Min. Felix Fischer, decisão monocrática, J. 01.02.2021, Pub. 04.02.2021.

25 STJ, AgRg-CC 148.391/DF, 3a Seção, Rel. Min. Joel Ilan Paciornik, J. 14.06.2017, DJe 27.06.2017.

26 Nesse sentido, a ponderação de Badaró (ob. cit., p.176), para quem "a expressão 'influir' é demasiadamente ampla, até mesmo porque não se define o grau de influência necessária para caracterizar o nexo entre as infrações a impor a união dos processos". 
e impreciso de conexão de causa" 27 . Não será por isso, contudo, que se terá por justificada a conexão ao aceno da menor ressonância ou do tangenciamento ocasional dos elementos de prova envolvidos em processos diversos.

A porosidade do tecido normativo não deixará de ser, bem sabemos todos, convite aberto às predileções, conveniências e contingências políticas do momento. E a escolha do juízo que definirá, por exemplo, o destino do inimigo da ocasião não escaparia da mesma sorte. Mas, feito o inevitável registro, parece ter se formado algum consenso na jurisprudência nacional em torno de uma densificação possível do conceito legal da influência probatória exigida ao reconhecimento da conexão trazida no inciso III do art. 76 do Código. Trata-se da exigência de que os fatos se entrelacem em uma unidade de sentido ${ }^{28}$.

Em síntese, a conexão probatória se verificaria naqueles casos em que os fatos encaminhados no processo somente adquiram um sentido apreensível quando conectados a outros. É dizer, quando o olhar da perspectiva assuma uma relevância tal que o exame isolado dos fatos esteja manifestamente comprometido.

Nesse sentido, recolheram-se duas decisões que, mais que representativas do consenso mencionado, ganham relevância na medida em que minudenciam a ideia, e fornecem exemplos claros do que se vem a dizer. A primeira, do Supremo Tribunal Federal, a segunda, do Superior Tribunal de Justiça, e que refaz, didaticamente, o caminho que conecta a primeira à segunda investigação ali em questão.

É ler o preceito legal. Não se contenta ele com mera utilidade probatória da reunião de ações, como a prática forense tende a fazer. Assim, por exemplo, se se estivesse investigando vários homicídios atribuídos a jagunços contra posseiros ou invasores de terra, no Bico do Papagaio, talvez fosse muito útil que, para caracterizar a ambiência, as causas da violência naquela região, por tais questões de terra, que se unissem os processos. Mas isto não é a conexão instrumental que o Código, autoriza, como está claro no inciso III do artigo 76. Existe a conexão, que se diz processual ou instrumental,

27 FREDERICO MARQUES, Elementos de direito processual penal I, p. 259. Para o referido autor (ob. cit., p. 258-259), "a reunião de processos, em tal hipótese, depende em muito do prudente critério do juiz, pelo que a decisão que ordena o simultaneus processus, em virtude da conexão probatória entre duas ou mais infrações, traz em si, como ensina Ugo Aloisi, 'una certa arbitrarietà di valutazione'".

28 Nesse sentido a lição da Espíndola Filho (ob. cit., p. 170): "Realmente, o art. 76, III, do CPP dispõe que haverá conexão quando a prova de um crime influir na prova de outro(s), sem especificar que é imprescindível haver entre eles uma relação de necessária prejudicialidade. Nessa ordem de ideias, penso que a conexão deve ser entendida como o nexo que os fatos ou coisas têm entre si. Desde que os crimes formem uma espécie de unidade, no mesmo contexto delitivo, é recomendável o julgamento conjunto de processos, para que as luzes, alcançadas sobre um deles, possam esclarecer a justiça, quanto ao outro". 
"quando a prova de uma infração ou de qualquer de suas outras circunstâncias elementares influir na prova de outra infração"; não é qualquer circunstância de uma infração que acaso seja útil, concretamente, ao deslinde das circunstâncias de outras, que determinará essa conexão instrumental. Um exemplo típico, que se enquadra perfeitamente no texto legal, é o da reunião num mesmo processo, da ação penal por furto com a correspondente à receptação da coisa: aí, a prova de uma infração, na medida em que esta infração é pressuposto da existência da outra, influirá na prova dessa infração acessória. A prorrogação de competência, por força de conexão probatória, é aceita quando houver dependência ou vínculo existente entre os fatos, desde que formem uma espécie de unidade, para que o julgador tenha visão uniforme do quadro probatório, evitando-se decisões díspares. ${ }^{29}$

[...] A prorrogação de competência, por força de conexão probatória, é aceita quando houver dependência ou vínculo existente entre os fatos, desde que formem uma espécie de unidade, para que o julgador tenha visão uniforme do quadro probatório, evitando-se decisões díspares. 5. Não há ilegalidade no aresto combatido no ponto em que reconheceu conexão como critério de fixação da competência por prevenção, pois, deveras, apesar das múltiplas ações penais, a prova de um crime influencia significativamente na prova de outros, uma vez que todos fazem parte do mesmo esquema criminoso, o qual, em razão de sua amplitude, deu ensejo ao desdobramento das investigações. O art. 76, III, do CPP não define o grau de interferência das provas nem estabelece imprescindível relação de prejudicialidade entre os delitos.

6. Correta a distribuição, por prevenção, da denúncia oferecida em desfavor dos recorrentes, derivada da Operação Fatura Exposta. Além de a competência absoluta, de natureza material, estar preservada, existe conexão instrumental vis-à-vis a influência entre uns e outros delitos apurados na anterior Operação Calicute, visto que todos os fatos formam uma unidade e possuem como gênese a obtenção de vantagens indevidas por meio de atividades ilícitas de idêntica organização criminosa, estruturada com o propósito de cobrar percentual de propina em contratos públicos do Estado do Rio de Janeiro, com a posterior dissimulação dos ativos ilícitos amealhados.

[...] Os atos de corrupção, pertencimento a organização criminosa e lavagem de ativos, portanto, foram praticados no mesmo tempo e lugar. Eles formam uma unidade, visto que fazem parte de imenso esquema de corrupção instalado no governo estadual. Não há como negar a relação parte/todo 
entre os fatos, que poderão ser melhor reconstruídos perante um único juiz, que detém a mesma competência predeterminada dos demais Juízos Criminais, todos titularizados por magistrados que ingressaram no cargo por meio de concurso público que devem atuar de forma imparcial e independente. A prevenção por conexão propiciará economia e celeridade na prestação jurisdicional e evitará a prolação de decisões conflitantes, interesses não só do juiz e do Ministério Público, mas também da defesa. ${ }^{30}$

Veja-se, aliás, que a unidade de sentido entre os fatos é precisamente a razão essencial embutida na previsão legal do crime continuado ${ }^{31}$ (art. 71, caput do (P), que fará incidir a continência, e, portanto, a reunião de processos sob o fundamento do risco de decisões contraditórias. Naturalmente, contudo, o fato de se tratar, no caso da conexão, de fatos imputados a agentes diversos pode, em tese, alterar o cenário do risco em questão.

Esclareça-se: embora a já adiantada noção de unidade de sentido (ou a relação parte/todo entre processos) pareça justificar, na maioria dos casos, a reunião dos processos, no caso da conexão, nem sempre essa justificativa parece se originar da possibilidade de pronunciamentos judiciais contraditórios. Não há dúvidas de que a atividade jurisdicional esteja, assim, otimizada, com o melhor e mais aprofundado esclarecimento dos fatos e a identificação possivelmente ampliada de sua autoria (dos fatos). O risco de decisões conflitantes, contudo, parece estar localizado em questão outra e bastante particular.

Em síntese, pensamos que a questão decisiva na afirmação do risco de decisões contraditórias possa ser reconduzida a um ponto: a dependência lógica entre os fatos (supostamente) constitutivos do injusto penal. Trata-se, assim, de substrato frequente nas hipóteses de conexão objetiva. Isso porque jamais será possível, por exemplo, a condenação por lavagem de dinheiro alegadamente obtido do tráfico de drogas quando se tiver provado, no decorrer da apuração deste último, a inexistência dos fatos. O que ocorrerá, aliás, qualquer que seja o crime antecedente, em tais condições. Parece evidente, nesses casos, a possibilidade de decisões contraditórias.

30 STJ, RHC 93.295/RJ, 6a Turma, Rel. Min. Rogerio Schietti Cruz, J. 16.08.2018, DJe 28.08.2018.

31 "Art. 71. Quando o agente, mediante mais de uma ação ou omissão, pratica dois ou mais crimes da mesma espécie e, pelas condições de tempo, lugar, maneira de execução e outras semelhantes, devem os subseqüentes ser havidos como continuação do primeiro, aplica-se-lhe a pena de um só dos crimes, se idênticas, ou a mais grave, se diversas, aumentada, em qualquer caso, de um sexto a dois terços. (Redação dada pela Lei $n^{0} 7.209$, de 11.07.1984)" 
Como também será o caso do exemplo clássico da receptação em relação ao furto, contrabando ou descaminho. Ou ainda da apuração do crime de frustração do caráter competitivo de licitação obtida com o auxílio de documento cuja falsificação é investigada em processo outro ${ }^{32}$. É possível imaginar, ainda, a lesão corporal ou o homicídio de um segurança profissional que somente se justificaria diante de um estupro de um terceiro, efetivamente almejado. Não sendo possível a configuração do concurso formal ou do crime continuado, a hipótese seria de conexão, e o risco de decisões conflitantes parece evidente.

Relembre-se, contudo, que uma coisa é afirmar a dependência recíproca entre delitos (ou de somente um em relação aos demais), outra é exigir que essa dependência esteja articulada teleologicamente (por meio de um vínculo de finalidade), como exige a conexão objetiva. Já se afirmou, linhas atrás, com o exemplo das lesões corporais recíprocas, que a possibilidade de decisões conflitantes não se limita a uma dependência dessa natureza (na terminologia de Galdino Siqueira, "relação de causa e efeito diretamente estabelecida"), mas engloba, igualmente, aquela ocasionalmente estabelecida, para ficarmos em igual dicionário. E convém relembrar igualmente que tais hipóteses, embora não atraiam a incidência do inciso II do art. 76, se adequam àquela prevista no inciso III, uma vez que a "prova de uma infração" certamente influirá, nesses casos, "na prova de outra infração".

Por fim, e uma vez mais, não se está com isso recusando qualquer proveito à reunião de processos nas hipóteses em que não esteja presente o risco de pronunciamentos judiciais contraditórios. Veja-se, por exemplo, o caso do concurso de crimes praticados em localidades circunscritas em comarcas diversas, praticados por diversos agentes (cada delito executado por um agente diferente), mas planejados por todos em conjunto. Embora não se visualize aí um risco semelhante, parece inegável que a reunião dos processos para instrução e julgamento conjunto permitirá, com a visão da unidade, um amplo e otimizado conhecimento da autoria e das circunstâncias dos fatos. Segundo já se registrou, aliás.

32 A eventual consunção do crime de falso somente importaria ao final do processo, como regra de julgamento, de aplicação de pena. Até a sentença, contudo, pensamos que a reunião de processos se justifica com base na conexão, e não na continência, uma vez que, constatado que a potencialidade lesiva do falso não se esgote no crime licitatório, o concurso de crimes que se terá verificado será o material, não o formal. 


\section{Referências}

ESPÍNDOLA FILHO, Eduardo. Código de Processo Penal brasileiro anotado. Campinas: Bookseller, 2000.

FIGUEIREDO DIAS, Jorge de; BRANDÃO, Nuno. Sujeitos processuais penais: o Tribunal. Coimbra, 2015. Disponível em: <https://apps.uc.pt/mypage/files/nbrandao/1083>. Acesso em: 24 jun. 2021.

FLORIAN, Eugenio. Elementos de derecho procesal penal. Barcelona: Bosch, 1934.

FREDERICO MARQUES, José. Elementos de direito processual penal. Campinas: Bookseller, v. I, 1997.

LOPES JÚNIOR, Aury. Direito processual penal e sua conformidade constitucional. 2. ed. Rio de Janeiro: Lumen Juris, v. I, 2008.

OLIVEIRA, Eugênio Pacelli de. Curso de processo penal. 23. ed. São Paulo: Atlas, 2019. XAVIER DE ALBUQUERQUE, Francisco Manoel. Ainda sobre a conexão: utilidade e atualidade de uma lição centenária. Revista de Doutrina e Jurisprudência, Brasília, n. 1, p. 33-46, 1966. Disponível em: https://bd.tjdft.jus.br/jspui/handle/tjdft/35180. Acesso em: 25 jul. 2021.

\section{Conflito de interesses}

Os autores declaram a ausência de conflito de interesses na produção do presente trabalho.

\section{Sobre os autores:}

Eugênio Pacelli de Oliveira | E-mail: eupacellioliveira@gmail.com Doutor em Direito (UFMG). Professor (IDP/DF). Advogado.

Matheus Oliveira de Carvalho | E-mail: matheusocarvalhoadv@gmail.com Mestre em Direito (UFMG). Advogado.

Recebimento: 10.11 .2021

Aprovação: 27.12.2021 